\title{
Evaluating stakeholders preferences: reconciling heritage and sustainability
}

\author{
N. A. W. Abdullah Zawawi ${ }^{1}$ \& A. Abdullah ${ }^{2}$ \\ ${ }^{1}$ Civil Engineering Department, \\ Universiti Teknologi PETRONAS, Malaysia \\ ${ }^{2}$ Kulliyyah of Architecture, \\ International Islamic University Malaysia, Malaysia
}

\begin{abstract}
The subsistence of traditional shophouse is threatened by demolition, unsympathetic changes and rapid redevelopment pace. Most often, the decisions pertaining to redevelopment of this built heritage are based on guidelines unrepresentative of the multi-cultural society in Malaysia. Involvement of direct stakeholders, namely owners and tenants, are minimal in the decision process. This paper provides an objective evaluation for the traditional shophouse redevelopment, incorporating multiple stakeholders' preferences. It focuses on exploring conflicts and values of the stakeholders using Multiple Criteria Analysis, or MCA technique. Using a common MCA technique, the Analytical Hierarchy Process, or AHP, stakeholders' preferences on a set of criteria for redevelopment decision are derived and compared. It is found that stakeholders' preferences are dissimilar even within their homogenous groups. This study contributes to discovering the potential of MCA to increase transparency in redevelopment decisions involving built heritage and multiple stakeholders.
\end{abstract}

Keywords: conservation area, Kuala Lumpur, redevelopment decision, traditional shophouse, stakeholders, multi-cultural society, MCA, AHP.

\section{Introduction}

Jacobs [1] believed that to a sustainable city embraces its past in future planning. The past gives a sense of belonging to a society, balancing progressive development with conservation of cultural values within its society $[2,3]$. Cultural values of a society are strongly associated with the physical structures, 
particularly the buildings $[4,5]$. Architectural details of each building reflect the changing eras. Malaysia built heritage is of recent vintage when compared to world heritage city such as Jordan's Petra. Nevertheless, it should be protected. Individually, a built heritage may not be spectacular but together with its intangible resources, such as multiculturalism and ethnic diversity, they are part of the future generations. Development that continually replaces these buildings with modern structures will diminish the cultural values and disintegrate the society [6], whereby intangible heritage such as local festivities will be celebrated with less vigour. In Kuala Lumpur, redevelopment and conservation is a quandary. Conservation of traditional shophouse is strongly opposed by market pressure biased on economically highest and best land use. The zoning of older areas into commercial property intensifies the redevelopment pressure on this built heritage [7]. The threat of obsolescence requires traditional shophouse owners to decide on the extent of redevelopment: adaptive reuse, rehabilitate, façade conservation or total redevelopment. Conversely, total redevelopment creates an opportunity to eliminate substandard buildings, incompatible land uses and other unwanted elements [8,9]. Increasing land prices render urban redevelopment as an attractive economic proposition. The surrounding communities also indirectly benefit from redevelopment of a site [10]. Then again, social function of a city is just as important. Total redevelopment is commonly associated with gentrification, displacing the original community and thus destroying the social integrity in most cases [11]. The minority groups are often removed from the redeveloped areas [12] and the decision made for the greater good easily lose sight of its objective [13]. However, urban redevelopment as defined in this research could revive the social life of a place. In this respect, adaptive reuse and façade conservation are sustainable options to total redevelopment because they cause less social disturbance; a quicker and cheaper options to improve the quality of the building stock; and a better sustainable approach to urban redevelopment: it uses existing resources and produces less construction and demolition wastes [14]. Minimal social disruption is particularly important for older inner city areas because of existing community and its association with built heritage.

This paper is part of an ongoing research to provide an objective evaluation for traditional shophouse redevelopment, incorporating multiple stakeholders' preferences. It explores conflicts and values of the stakeholders using Multiple Criteria Analysis, or MCA technique. The study is dedicated to provide a mechanism to elicit and objectively evaluate respondents' interests and values. These differences are now measurable, comparable and if wished to, can pave ways for further discussion to understand the issue. It will act as preliminary findings for political decision makers to further explore the conflict and reasons behind the conflict, thus promote a transparent and consensual decision environment.

\subsection{Redevelopment vs. conservation}

As Malaysia made its place in the global economy, Kuala Lumpur or KL, experiences rapid growth far ahead of other local cities [15]. Demands for more 
space made older areas potential developable land via urban redevelopment. The Government initiated integration of KL's economy with the global economy in 1980. By 1995, KL Stock Exchange or KLSE is ranked fifth in the Asia Pacific Region after Tokyo, Osaka, Hong Kong and Australia [15] propelling KL as a center for trade, finance and commerce. Commercial land use increased more than 25 percent from 1984 to 2000 whilst other land uses decreased [7]. Rapid growth resulted in substantial and sometimes irreversible changes to its built form and socio-cultural character. The existing space, a legacy of colonial immediate past decisions, however represents different socio-economic, political forces and circumstances. The conservation guidelines impose on these older areas are perceived as unnecessary obstacle. Some owners want the freedom to express their business identities via the outlook of their premises but others such as the pro-conservation groups opine that the original urban character should be conserved to maintain KL's unique urban identity [5]. Generally, the conservation guidelines emphasize on architectural significance whereas there exist many other aspects which could be objectively considered in decisions to redevelop culturally significant urban areas.

\subsubsection{Public involvement in redevelopment decisions}

The involvement of multiple stakeholders in urban planning is an important part in sustainable future [16]. Successful urban redevelopments in many countries show that they were initiated and driven mainly by the community themselves [12, 17-19]. Unfortunately, the current planning decisions in Malaysia are exclusive to a group of stakeholders. Community participation in redevelopment is minimal [20]. Public participation in planning decisions is at best, mere formality, exemplified by the gazetting of the Kuala Lumpur Draft Local Plan, KLDCP [21]. The members of the public are not consulted until the public viewing of the draft plan. The subsequent processes from public objections to public hearing and report on the recommended changes to the Mayor are ineffective because the final decision lies exclusively with the Mayor.

\subsubsection{Multicultural heritage}

KL's distinctive local identity is entrenched in the traditional shophouse. Diverse cultural influences are clearly manifested in the architectural details. The Malaysian built heritage is largely regarded as the product of a colonial plural society $[22,23]$. The traditional shophouse with covered kaki lima (literally five foot) way is unique to early urban settlements in Southeast Asia, particularly Malaysia, Singapore and Thailand. The kaki lima is an adaptation to the local climate, hot humid and torrential rain. This oldest extant urban settlement is the repository of lifestyle from different era of small-scale economy and life style that ironically nurtured the current economic success. Apart from the market and places of worship, traditional shophouse is one component of early major towns in Malaysia [24]. Many have played a central role in the life of a city for almost a century. Its floor space was designed to cater for the needs of the then urbanites. The ground floor is business use, whereas the top floor is residential. Over the years, traditional shophouse has played a major role in meeting housing needs for urban dwellers [6]. It was extremely convenient for traders and merchants to 
live close to their workplace. When the merchants relocate to the more conducive suburbs, the vacant residential quarters were then converted into worker's quarters or rented outs. This arrangement has silently supported economic growth and helped businesses to sustain for generations in the rapidly developing city center.

\subsection{The study area}

The City Hall of Kuala Lumpur or CHKL has been rather proactive in protecting heritage buildings and areas [25]. CHKL has drafted a local plan that defines three heritage zones within the inner city center: Primary, Secondary and Tertiary Heritage Zones, referring to the level of conservation enforcement. The Secondary Zone encompasses an area that is "less contiguous and contains mixture of newer and older buildings with significant historic merit". The zone is the oldest commercial area, where the most number of traditional shophouse with historical and/or architectural merits are located. It is populated with Category 3 heritage buildings: buildings with "elements or characteristics of some historical or architectural significance which are recommended to be conserved" [21].

\section{The methodology}

The methodology in this study consists of two stages: Multiple Criteria Analysis to elicit and rank stakeholders' preferences followed by Consensus Building that establishes the correlation among those rankings.

\subsection{MCA technique}

MCA is not a singular tool to measure different aspects in sustainability [13]. However, it was chosen for a number of reasons. MCA effectively decomposes a decision problem in a structured manner. The process of assigning weighting factor to each criterion [26] and the need to justify criteria and weight choices can contribute to openness, traceability and accountability in the decision making process. It enables stakeholders to learn about their own preferences and of others as well. Transparency in decision making is increasingly demanded in public and private decisions that affect scarce public resources such as land and its associated uses. MCA method provides insight into how different individuals approach a decision problem as well as areas and intensity of consensus or conflict among individuals. One of the popular MCA methods is the Analytical Hierarchy Process or AHP proposed by Saaty [27]. The working principles of AHP comprise of decomposition, comparative judgment and synthesis of priorities via three basic steps: model building, pairwise comparison and ranking. A set of criteria is established and decomposed into different levels of independent elements, with increasing degree of specificity, known as a decision hierarchy (Figure 1). The criteria will be used to evaluate the alternatives. Comparative judgment compares the relative importance of one decision criterion to another in the same level pairwise. Stakeholders will assign weights 
to each criterion according to their preferences on a scale that ranges from equal importance to extreme importance, represented by numbers 1 to 9 respectively. Even numbers are considered as intermediate points between adjacent values. The weights are then synthesized to obtain ranking.

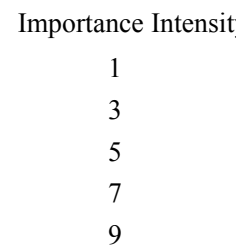

Definition

Criteria $\mathrm{i}$ and i`are equally important

Criterion $\mathrm{i}$ is moderately more important than criterion $\mathrm{i}$

Criterion $\mathrm{i}$ is strongly more important than criterion $\mathrm{i}$

Criterion $i$ is very strongly more important than criterion $i$

Criterion $\mathrm{i}$ is extremely more important than criterion $\mathrm{i}^{\mathrm{i}}$

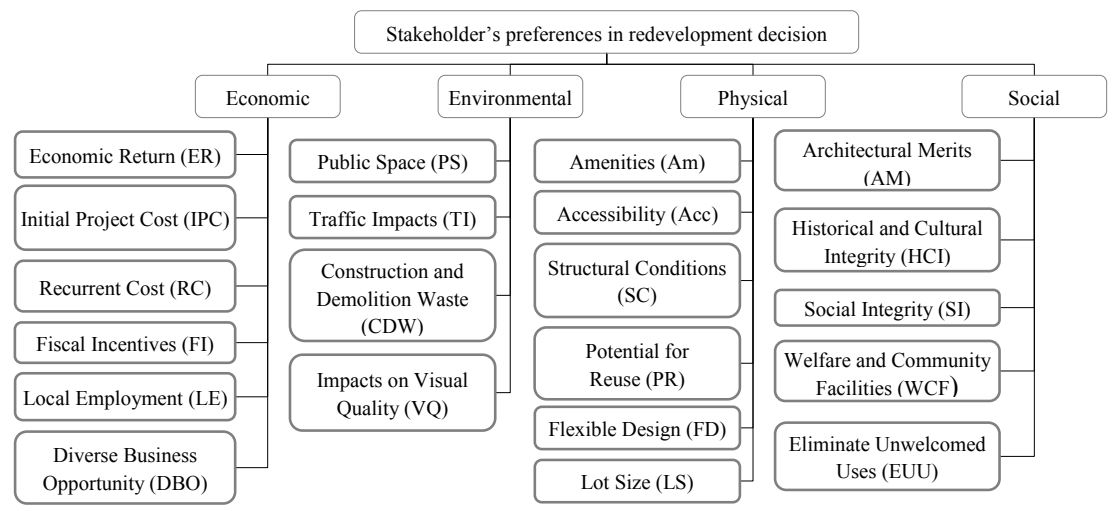

Figure 1: Redevelopment decision problem decomposed into decision hierarchy.

The strength of AHP is that decision makers are assumed to be inconsistent in their values and judgments. The method measures this inconsistency to help the stakeholder(s) learn more about the decision in question and of their own and others' biases and inconsistencies. Inconsistency Ratio $<0.10$ indicates a reasonable level of consistency. Ratio $\geq 0.10$ suggest revising the original pairwise comparison values.

\subsection{Consensus building}

Consensus building is established by creating awareness among the stakeholders of the differences within the group. It captures and subsumes conflict balancing or consensus building within the redevelopment decision process. However, in situations where stakeholder objectives and priorities are in conflict, it is difficult in practice to reach agreement on the relative importance of individual criterion. In these cases, it is more appropriate to explore the various dimensions of the conflict, as represented in criteria choices and weightings, by producing group rankings that are based on the ranks generated by individual group members. To 
test the significance of the association between pairs of stakeholder criteria rankings and between the ranks for individuals, Spearman's rank correlation coefficients $\left(r_{s}\right)$ were calculated for the rankings of criteria by stakeholders. The test statistic assumes that at least five pairs of observations are present and that the observations are ranked from 1 to $n$ with many tied ranks being represented by average ranks [28]. Assuming that the number of pairs of tied ranks does not exceed 25 percent of $n$, the statistic has the following form [28]:

$$
r_{S}=\left(\frac{6 \sum_{i=1}^{n} d_{i}^{2}}{n^{3}-n}\right)
$$

where: $d_{i}^{2}$ is the squared difference between the rank for alternative $I ; n$ is the number of observations. When $n$ is greater than 10, the distribution of $r_{s}$ approaches the $t$ distribution allowing the significance of $r_{s}$ to be tested against critical values of $t$ as a value of $t$ with $n-2$ degrees of freedom [29]. The transformation of $r_{s}$ values to Student's $t$ is calculated by:

$$
t=r_{S} \sqrt{\frac{n-2}{1-r_{s}^{2}}}
$$

\subsection{Data collection}

The overall approach of this paper involves survey using questionnaire to identify stakeholders' preferences or priority for each criterion. The preferences indicated by each stakeholder are subsequently compared pairwise to other stakeholders. The consistency of evaluation is maintained through moderation by the same researcher who, while guiding the stakeholders through their input on preferences, was careful not to bias any aspect of the process. The sampling is done based on purposive sampling, meaning only selected individuals is chosen as respondent. The questionnaire comprises three parts: the particulars of the respondent, preference weightage and open ended feedback on the criteria. The second part defined criteria weighting. The questionnaire survey was conducted as structured interview. Respondents were given a detailed explanation about the survey. Each criterion was explained in detail to ensure respondents have common understanding of the key terms and criteria to be weighed. The respondents are allowed to ask questions to remove ambiguities. This process is crucial to ensure consistent interpretations of the terminology so that the results can be analyzed in a meaningful way. Twenty individuals were approached for the structured interview but only nine responded. They are lay people, representing the community made up of owners and tenants in the study area. They were chosen based on the premise they occupy, namely the traditional shophouse within traditional commercial area undergoing rapid redevelopment nearby and in the surrounding areas. 


\section{MCA framework for redevelopment decisions}

\subsection{The stakeholders}

A stakeholder is a person who is involved in or affected by a course of action determined by a decision. The stakeholder's involvement as decision maker are often classified in relation to the level where decisions are made i.e. national, regional or local levels, the scale and durability of their decisions. Stakeholders can be classified based on the effect of the decision making [30] or decision contexts [31]. In this study, the stakeholders are the owner and/or tenants. The 'owners' in this study are the people carrying out business activities within the area. The study classifies the landowners/tenants in older Kuala Lumpur to be in "direct group with homogenous decision making context" [32]. The stakeholders have direct interest in the use and value increase of the building and their common objective is to optimize the land into highest and best use.

\subsection{The criteria}

Based on literature and discussion with various stakeholders within the City Center, the study selected twenty-one criteria that are relevant to redevelopment decisions [32]. The selection criteria must be as broad as possible to equally represent all aspects of consideration, encompassing economical, social and environmental/physical dimensions, but not too broad that the evaluation becomes too complicated, leading to increased inconsistency in judgment and uncertainty [33]. The MCA technique was applied to rank the relative importance of each criterion based on each individual's preferences and underlying objectives. The consensus analysis determines the correlation strength of those rankings.

\section{Research findings}

The fundamental elements of consensus and conflict in multiple stakeholder decision making are shown in Figures 2-5 and Table 1: the extent of agreement concerning the criteria for redevelopment decision and differentials in the relative importance of individual criteria, as expressed through weight settings. Figure 2 shows the average criteria weightage for all nine stakeholders. Economic Return is weighted as the most important by eight stakeholders; six of them give the highest priority to this criterion. There is more than 60 percent gap between Economic Return and the next most important criterion. This is followed by another three criteria in economic: Diversity in Business Opportunity, Fiscal Incentives and Local Employment, as shown in Figure 3. It is evident from the priority weights assignment that economic aspect is the most important factor to owners and tenants in the case study area. At the other end of the bar chart, three criteria are least preferred by the stakeholders: Architectural Merits, Historical/cultural Integrity and Social Integrity. Overall there are six least important criteria as shown in Figure 4. Eight of nine stakeholders consider Architectural Merits as the least important. 


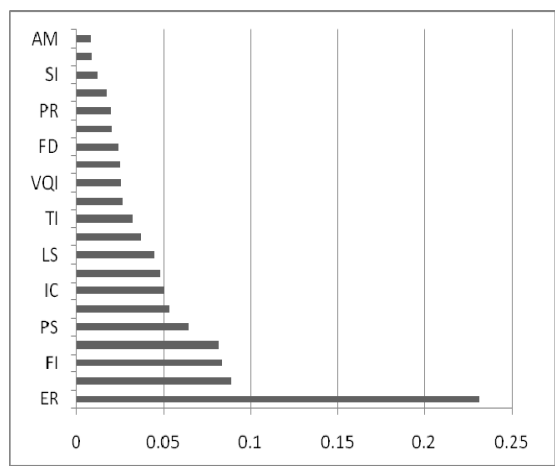

Figure 2: Overall weightage Figure 3: preferences.

Legend: See Figure 1

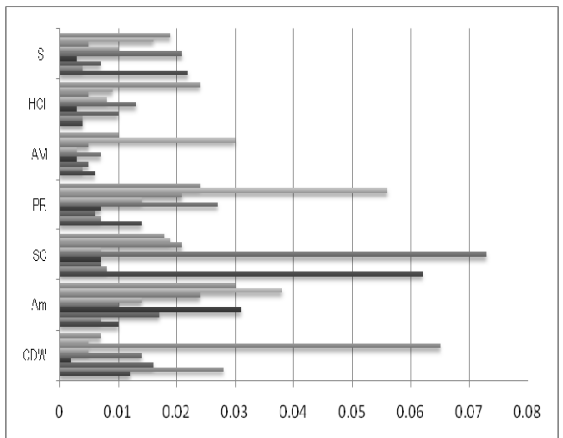

Figure 4: Criteria given lowest weightage by at least three stakeholders.

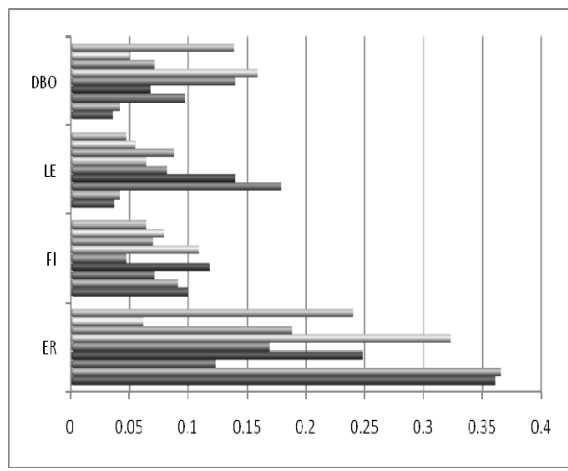

Criteria given highest weightage by at least three stakeholders.

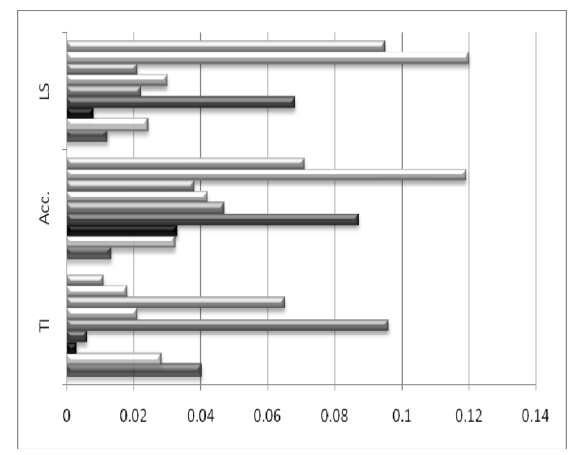

Figure 5: Criteria given mixed weightage.

Many stakeholders feel that conservation of these values is mainly the responsibilities of the Government and local authorities. Unless the benefits can be made tangible in some ways to benefit their businesses, they do not think these criteria are important. However, many verbally express willingness to cooperate in conservation efforts. Figure 5 shows three criteria that receive mixed weightage, meaning it was ranked highly important by some and of low importance by other(s). Two stakeholders feel that Lot Sizes is an important criterion. One stakeholder thinks it is the least important, where as the other six give medium priority. Comparatively, this group of stakeholders is more homogenous compared to Professionals [32], which gives mixed weightage to five criteria: Amenities, Flexible Design, Lot Sizes, Structural Conditions and Welfare and Community Facilities. 
Some understanding of each stakeholder's objectives and concerns is required to understand the origin of conflict and the rationale underlying criteria weights. Many of the owners/tenants have been operating for more than 15 years. Until the year 2000, traditional shophouses are classified as controlled premise under the Control of Rent Act 1960 (Repealed 2000). Overhead costs are low, allowing businesses to sustain despite rapid redevelopment in the surrounding areas. However, low rent gives little incentives for owners to properly maintain their premises. This has led to dilapidated states of traditional shophouses and the surrounding areas. The stakeholders wish to continue operating their businesses in the same premise regardless of whether redevelopment takes place or not. However, majority stressed the need for more public spaces and better access to the area. Owners and tenants in general perceived that conservation is the responsibility of the Government, and the planners and architects in the City Hall. They are willing to give their supports in terms of cooperation and following the guidelines set by the authorities. Architectural, historical and social were considered of low importance. This lack of perceived importance could be because of inability to directly relate these criteria to economic gain. Many stressed on the improvement on area safety. This may be because crime rates are rather high in the city center, and as a major tourist spot, such issue would definitely have negative impacts on businesses.

Table 1 shows the correlations of the stakeholders' importance ranking for consensus building. From the importance ranking of 9 stakeholders, 36 pairwise comparisons, Stakeholder 1, S1 compares to Stakeholder 2 is denoted by S1-S2, thus formulated as $\mathrm{Si}-\mathrm{Sj}$., Pairwise comparisons are carried out to determine the strength and significance of correlations between the ranks. Pairwise $r_{s}$ values confirmed strong and significant positive correlations between ranks of importance for 24 pairs at $99 \%$ confidence level, except between 12 pairs shown in Table 1. Significant positive correlations at $95 \%$ confidence level are observed between 7 compared rankings in the table, marked by YES. Ranking of importance by Stakeholder 8 (S8) has insignificant correlations with three other stakeholders, S1, S3 and S7. Five pairwise comparisons have correlations below

Table 1: Correlations of stakeholders' importance ranking.

\begin{tabular}{|c|c|l|c|c|}
\hline $\begin{array}{c}\text { Stakeholder, } \mathrm{S}_{\mathrm{i}} \text { to } \\
\mathrm{S}_{\mathrm{i}},\end{array}$ & Rs & $\begin{array}{l}\text { Student's t- } \\
\text { statistic }\end{array}$ & Significant@95\% & Significant@99\% \\
\hline $\mathrm{S}_{1}-\mathrm{S}_{3}$ & 0.431818182 & 2.08684466 & YES & NO \\
\hline $\mathrm{S}_{1}-\mathrm{S}_{4}$ & 0.482792208 & 2.403058677 & $\mathrm{YES}$ & $\mathrm{NO}$ \\
\hline $\mathrm{S}_{1}-\mathrm{S}_{8}$ & 0.138311688 & 0.608737399 & $\mathrm{NO}$ & $\mathrm{NO}$ \\
\hline $\mathrm{S}_{1}-\mathrm{S}_{9}$ & 0.193181818 & 0.858226456 & $\mathrm{NO}$ & $\mathrm{NO}$ \\
\hline $\mathrm{S}_{2}-\mathrm{S}_{8}$ & 0.416883117 & 1.99915417 & $\mathrm{YES}$ & $\mathrm{NO}$ \\
\hline $\mathrm{S}_{2}-\mathrm{S}_{9}$ & 0.418181818 & 2.006699516 & $\mathrm{YES}$ & $\mathrm{NO}$ \\
\hline $\mathrm{S}_{3}-\mathrm{S}_{5}$ & 0.307142857 & 1.406804808 & $\mathrm{NO}$ & $\mathrm{NO}$ \\
\hline $\mathrm{S}_{3}-\mathrm{S}_{8}$ & 0.339285714 & 1.572167838 & $\mathrm{NO}$ & $\mathrm{NO}$ \\
\hline $\mathrm{S}_{3}-\mathrm{S}_{9}$ & 0.47012987 & 2.321838862 & $\mathrm{YES}$ & $\mathrm{NO}$ \\
\hline $\mathrm{S}_{5}-\mathrm{S}_{8}$ & 0.399350649 & 1.898704644 & YES & $\mathrm{NO}$ \\
\hline $\mathrm{S}_{7}-\mathrm{S}_{8}$ & 0.215584416 & 0.962339905 & $\mathrm{NO}$ & $\mathrm{NO}$ \\
\hline $\mathrm{S}_{7}-\mathrm{S}_{9}$ & 0.380519481 & 1.793571107 & YES & $\mathrm{NO}$ \\
\hline
\end{tabular}


95\% confidence level. S6 has strong and significant correlations at 99\% confidence level with all the stakeholders. Consistency Index, CI for both S8 and S9 are very high, 0.39 and 0.27 respectively, followed by S3 at 0.23 . The other stakeholders have CI equal or less than 0.1 .

The correlations between rankings of criteria by different stakeholders (Figures 2 to 5) are strong as indicated by Table 1. The analysis of the problem shows that this evaluation method works rather well in exposing individual and sub-group dimensions of commonality and to identify differences among individuals in a group. This study finds economic aspects as the main priority in redevelopment decisions followed by environmental aspect. Majority of the stakeholders share similar preferences. However, one third of the stakeholders have little in common with each other.

\section{Conclusion}

This paper has presented an MCA-based evaluation to urban redevelopment decision in culturally significant areas to uncover conflict and consensus in decision making. The decision-making evaluation developed in this study has potential for practical application. The framework developed in this paper may offer a way of facilitating community involvement in urban redevelopment process. The findings in this study suggested that even those with similar interests and decision contexts can have divergent views pertaining to the relative importance of the decision criteria. This is perhaps one of the major roots of disputes over urban redevelopment and conservation efforts in presentday society. The researchers acknowledge the limitation of this study in terms of generalization the findings to other cities or urban areas. Solutions attempted previously may have little relevance to another place and time. It is valuable to extend the investigation to explore whether stakeholders' preferences are project-, time- and/or location-specific.

\section{Acknowledgement}

We would like to thank the Universiti Teknologi PETRONAS for providing facilities to accomplish the work for this paper.

\section{References}

[1] J. Jacobs, The Death and Life of Great American Cities. New York: Vintage Books, 1961.

[2] F. Steinberg, "Conservation and rehabilitation of urban heritage in developing countries," Habitat International, vol. 20, pp. 463, 1996.

[3] F. Kaufman, "The End of Sustainability," International Journal of Sustainable Society, vol. 1, pp. 383-390, 2009.

[4] P. T. Fels, "Penang's Shophouse Culture," Places, vol. 9, pp. 46-55, 1994. 
[5] W. I. Wan Hashimah and S. Shuhana, "The Old Shophouses as Part of Malaysian Urban Heritage: The Current Dilemma," presented at 8th International Conference of the Asian Planning Schools Association, Penang, 2005.

[6] B. T. Khoo, "The Repeal of Rent Control: Requiem for Gerakan," vol. 2008. Penang, 2000.

[7] Kuala Lumpur City Hall, "Kuala Lumpur Structure Plan 2020," Author, Kuala Lumpur 2005.

[8] V. F. Chen, "Ideas and Trends in Conservation and Adaptive Reuse of Existing Building - KL Central Market: A Study," in Majalan Arkitek (Architecture Malaysia), vol. 3\&4, 1986.

[9] Rahim \& Co Research Sdn Bhd, "Battling Inner City Decay," in Housing \& Property, 2005, pp. 8-9.

[10] S. Zielenbach, The art of revitalization: improving conditions in distressed inner-city neighborhoods. New York: Garland Publishing Inc., 2000.

[11] N. Kleniewski, Cities, Change and Conflict: A Political Economy of Urban Life, third ed: Thomson Wadsworth, 2006.

[12] P. Dreier, "Boston's West End 35 years after the bulldozer," Planning, vol. 14, pp. 14-17, 1995.

[13] D. Lempert and H. N. Nguyen, "A Sustainable Development Indicator for NGOs and International Organisations," International Journal of Sustainable Society, vol. 1, pp. 44-54, 2008.

[14] C. Langston, F. K. W. Wong, E. C. M. Hui, and L.-Y. Shen, "Strategic assessment of building adaptive reuse opportunities in Hong Kong," Building and Environment, vol. 43, pp. 1709-1718, 2008.

[15] S. Morshidi and G. Suriati, Globalisation of Economic Activity and Third World Cities: A Case Study of Kuala Lumpur. Kuala lumpur: Utusan Publications \& Distributors Sdn Bhd, 1999.

[16] C. Tweed and M. Sutherland, "Built Cultural Heritage and Sustainable Urban Development," Landscape and Urban Planning, vol. 83, pp. 62-69, 2007.

[17] C. Landorf, "A Framework for Sustainable Heritage Management: A Study of UK Industrial Heritage Sites," International Journal of Heritage Studies, vol. 15, pp. 494-510, 2009.

[18] C. Aas, A. Ladkin, and J. Fletcher, "Stakeholder Collaboration and Heritage Management," Annals of Tourism Research, vol. 32, pp. 28-48, 2005.

[19] E. de Merode, R. Smeets, and C. Westrik, "World Heritage Papers 13. Linking Universal and Local Values: Managing Sustainable Future for World Heritage." Amsterdam, the Netherlands: UNESCO World Heritage Center, 2004.

[20] I. Zainah, "A Research on Urban Conservation: A Framework for Community Involvement in Malaysia," Malaysian Townplan, vol. 3, pp.44$51,2006$.

[21] Kuala Lumpur City Hall, "Draft Kuala Lumpur City Plan 2020," Author, Kuala Lumpur 2008. 
[22] P. T. Fels, "Conserving the Shophouse City," in The Penang Story International Conference 2002. The City Bayview Hotel, Penang, Malaysia, 2002.

[23] A. A Ghafar, British Colonial Architecture in Malaysia 1800-1930. Kuala Lumpur: Museums Association of Malaysia, 1997.

[24] J. M. Gullick, Old Kuala Lumpur. Shah Alam: Oxford University Press, 2005.

[25] W. A. Z. Noor Amila and A. Alias, "Urban Heritage Conservation Through Redevelopment Strategies: A Case Study Of Kuala Lumpur," presented at CSAAR08B, Petra University, Amman, Jordan, 2008.

[26] R. Janssen, Multiobjective Decision Support for Environmental Management. Dordrecht: Kluwer Academic Publishers, 1992.

[27] T. L. Saaty, The Analytical Hierarchy Process. New York: McGraw-Hill, 1980.

[28] S. Siegel and J. Castellan, N. John, Nonparametric Statistics for the Behavioural Sciences. New York: McGraw-Hill, 1988.

[29] C. D. Adams and H. G. May, "Active and Passive Behaviour in Land Ownership," Urban Studies, vol. 28, pp. 687 - 705, 1991.

[30] I. L. Z. Bacic, "Demand-driven Land Evaluation With Case Studies in Santa Catarina, Brazil," in Department of Earth Systems Analysis, vol. Ph.D: Wageningen University, 2003, pp. 155.

[31] R. D. Feick, "A Multi-participant Spatial Decision Support System for Planning Tourism-related Land Use Change in Small Island States," in Geography, vol. Ph.D. Ontario: University of Waterloo, 2000, pp. 228.

[32] W. A. Z. Noor Amila, A. Alias, and I. Arazi, "Sustainable Planning: Specifying Stakeholders' Preferences in Redevelopment Decisions for Conservation Area in Kuala Lumpur," in International Conference on Sustainable Building and Infrastructure (ICSBI'10). Kuala Lumpur, 2010.

[33] A. Alias, "An Integrated Method of MCDM and GIS for Land Use Planning and Environmental Resources Management," in Graduate School of Science and Technology, vol. Ph.D: Kumamoto University, 1994. 